EPiC Series in Engineering
Volume 3, 2018, Pages 1486-1494
HIC 2018. 13th International
Conference on Hydroinformatics

\title{
Evaluation of the uncertainty of flash flood prediction using the RRI model in mountainous rivers
}

\author{
Yosuke Nakamura $^{1 *}$, Koji Ikeuchi², Shiori Abe ${ }^{3}$, Toshio Koike ${ }^{1}$, \\ and Shinji Egashira ${ }^{1}$ \\ ${ }^{1}$ International Centre for Water Hazard and Risk Management (ICHARM), Public Works \\ Research Institute (PWRI), Tsukuba, Japan \\ ${ }^{2}$ Department of Civil Engineering, The University of Tokyo, 7-3-1, Tokyo, Japan \\ ${ }^{3}$ Mitsui Consultants Co., Ltd., 1-11-1, Osaki, Shinagawa-ku, Tokyo, Japan \\ y-nakamura4 4 @pwri.go.jp
}

\begin{abstract}
In recent years, flood damage caused by flash floods in mountainous rivers has been frequently reported in Japan. In order to ensure a sufficient lead time for safe evacuation, it is necessary to predict river water levels in real time utilizing a hydrological model. In this study, we conducted flood prediction using the RRI model and rainfall forecasted for the next 6 hours in the Kagetsu River basin $(136.1 \mathrm{~km} 2)$ in July 2017, evaluated the uncertainty regarding the prediction, and illustrated the results using a box-plot. The evaluation found that the mean error of the forecasted water level was approximately $0.3 \mathrm{~m}$ in the prediction for the initial 3 hours and $-0.97 \mathrm{~m}$ at the 6th hour. Also, the study investigated the possibility of correcting water levels forecasted by clarifying an uncertainty distribution. As a result, the water level forecasted was found to be underestimated because it was predicted to rise as high as Warning Level 2, while the water level forecasted with bias correction was predicted to reach Warning Level 4. Moreover, the lead time was estimated to prolong by 2 hours. Overall, the study suggested that flood forecasting can be improved by considering the uncertainty involved in prediction.
\end{abstract}

\section{Introduction}

In Japan, because of its steep terrain, river water levels rise sharply, and the lead time from rainfall to runoff is very short. Since flood discharge in a mountainous river can be more than 100 times as large

${ }^{*}$ Corresponding author, Tel.: +81-29-879-6779; Fax: +81-29-879-6709 
as that in normal times, flash floods are one of the main causes for disasters. In recent years, flood damage caused by flash floods in mountainous rivers has been more frequently reported throughout the country. Therefore, it is necessary to predict river water levels in real time to ensure a sufficient lead time for safe evacuation. However, flash flood prediction contains uncertainties because it includes many processes such as radar observation, water level observation, rainfall forecasting, hydrological modeling, and telemetering. In this study, we developed a pseudo environment for real-time flash flood prediction using the Rainfall-Runoff-Inundation (RRI) model. The purpose of this study was to quantitatively evaluate the error of flood prediction and to clarify the effect of flash flood prediction considering uncertainty.

\section{Study area and flood event}

\subsection{Target river basin}

In this study, the target river basin was the Kagetsu River basin in the Kyushu region of Japan (Figure 1). The Kagetsu River basin is a right tributary of the Chikugo River; the catchment area is $136.1 \mathrm{~km} 2$, the flow length is $16.6 \mathrm{~km}$, and the watershed is mostly covered with forests. It is a typical mountainous river in Japan. The Kagetsu River basin has a distinctive rainfall-runoff characteristic; it takes less than an hour from the peak of rainfall to the peak of water level. There is no dam with flood control function.

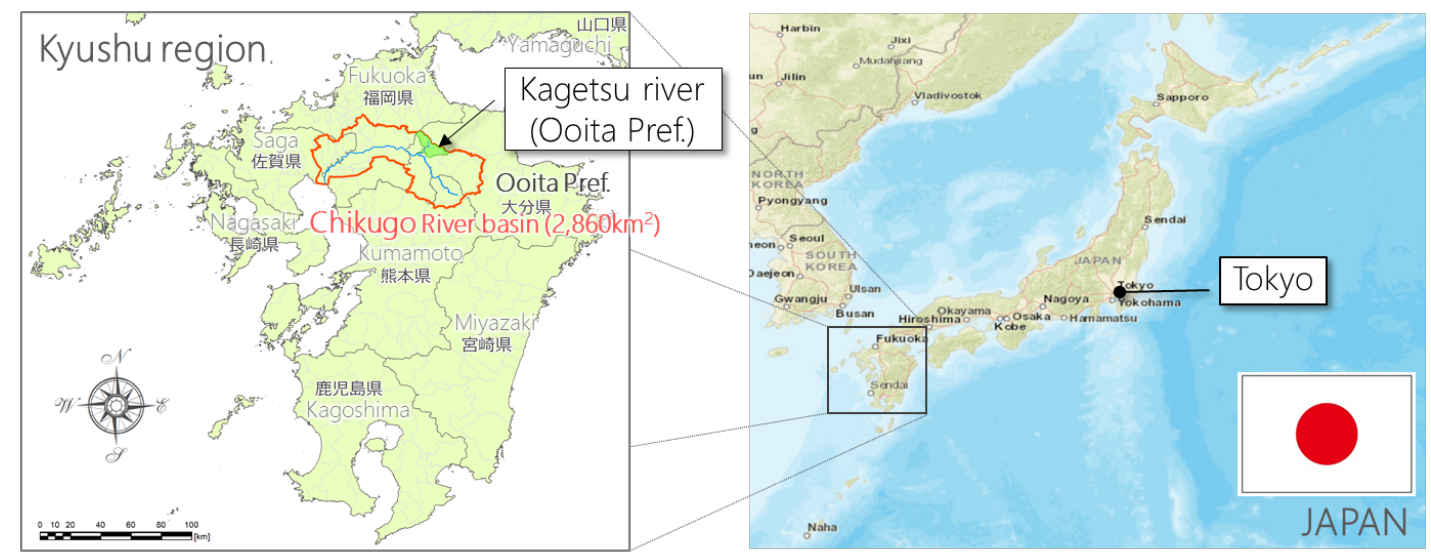

Figure 1: Location map of the Kagetsu River basin in the Kyushu region of western Japan. 
Evaluation of the Uncertainty of Flash Flood Prediction Using the RRI Model ... Y. Nakamura et al.

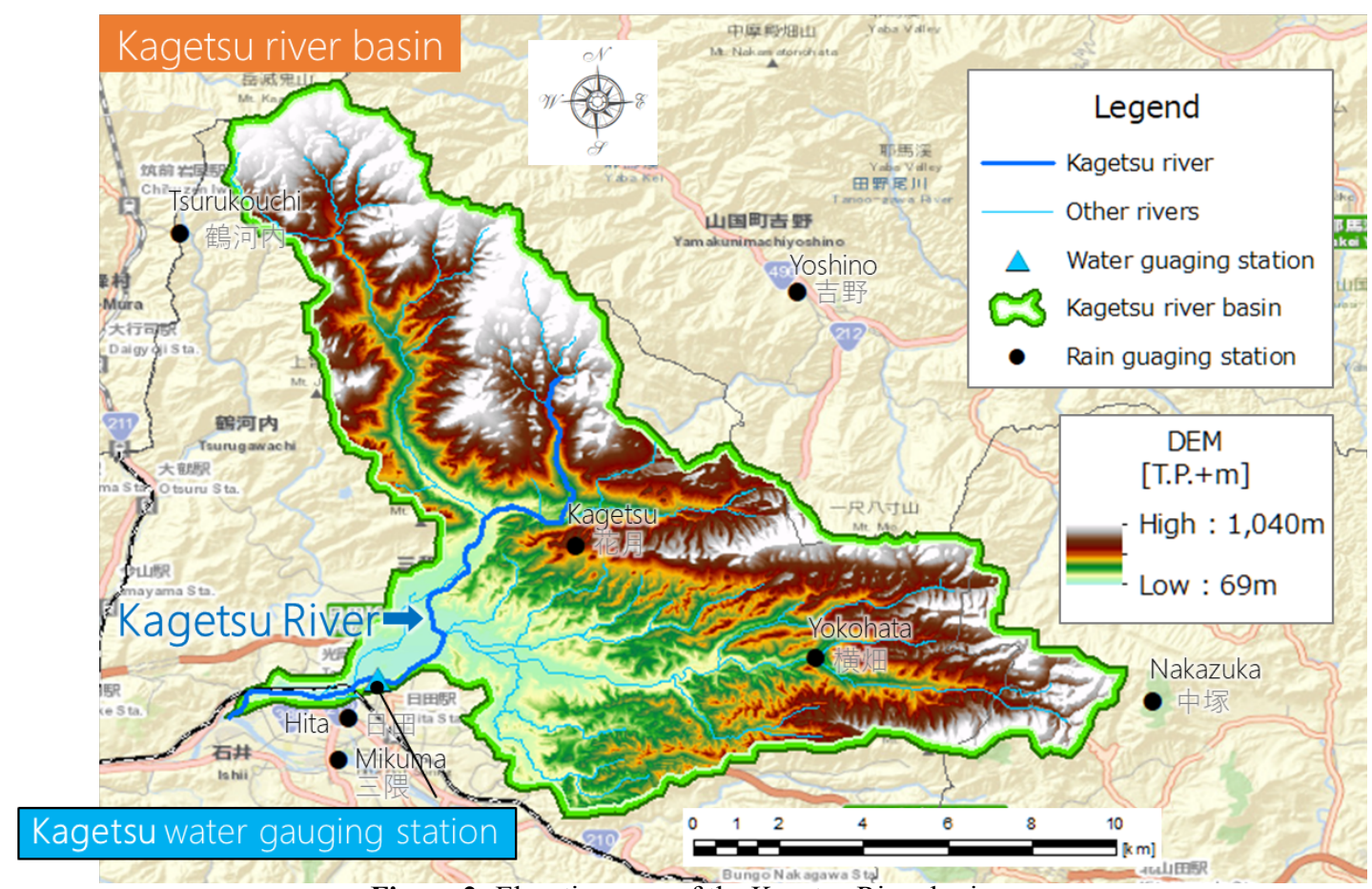

Figure 2: Elevation map of the Kagetsu River basin.

\subsection{Target river basin}

In the past several years, flooding caused by frontal precipitation occurred three times in this river on 3 July in 2012, 14 July in 2012, and 5 July in 2017. In the floods in 2012, part of the levee collapsed due to a sharp rise in water level, and serious flood damage resulted. Five years later in 2017, a flood recurred due to frontal precipitation and recorded the highest water level at the Kagetsu water gauging station. In this study, we targeted the July 2017 flood; this event caused by heavy rain due to a seasonal rain front. Warm moist air continued flowing in by a rain band, which resulted in the heavy rainfall for several hours in the same place. The peak rainfall of the average watershed precipitation was $53.5 \mathrm{~mm} / \mathrm{h}$, and the cumulative precipitation was $370 \mathrm{~mm}$.

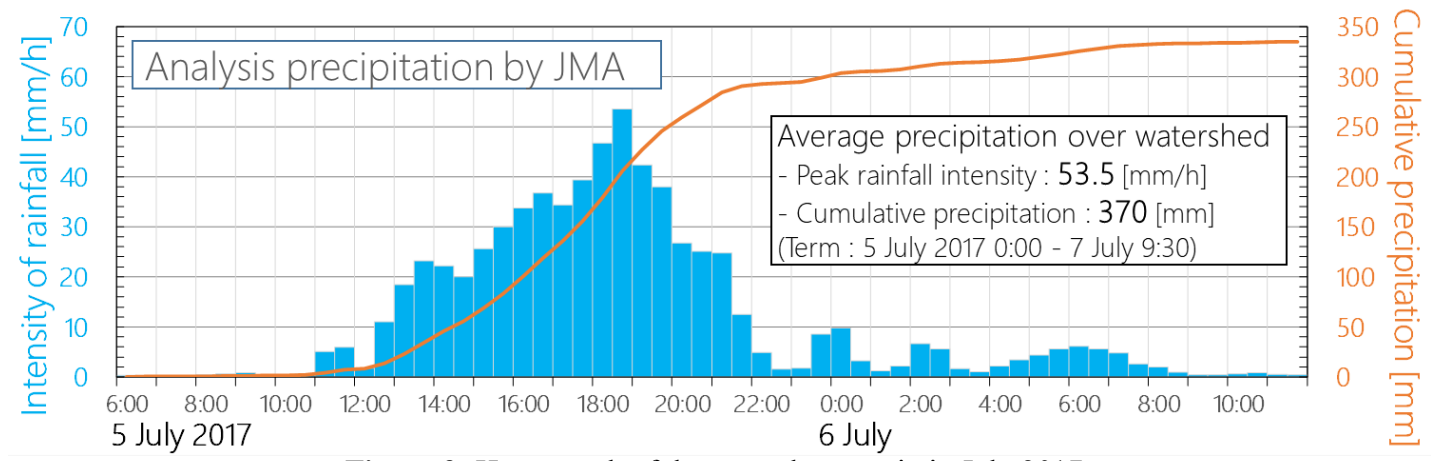

Figure 3: Hyetograph of the target heavy rain in July 2017. 
Evaluation of the Uncertainty of Flash Flood Prediction Using the RRI Model ... Y. Nakamura et al.

\section{Methodology}

\subsection{Hydrological model}

The RRI model $[1,2]$ was used as the hydrological model in this study. The conceptual scheme of the RRI model is shown in Figure 4. This model is a two-dimensional model capable of simulating the rainfall-runoff process and the flood inundation process simultaneously at a river-basin scale. The model deals with slopes and river channels separately; the flow on the slope grid cells is calculated with a 2D diffusive wave approximation, while the channel flow is calculated with a $1 \mathrm{D}$ diffusive wave approximation. For better representations of the rainfall-runoff-inundation processes, the RRI model simulates also lateral subsurface flow, vertical infiltration flow, and surface flow. The lateral subsurface flow, which is typically important in mountainous regions, takes into account both saturated and unsaturated subsurface flows. On the other hand, the vertical infiltration flow is estimated using the Green-Ampt model. The flow interaction between river channel cells and slope cells is estimated based on different overflowing formulae, depending on water-level and levee-height conditions. The RRI model was developed by ICHARM of the Public Works Research Institute and can be downloaded from ICHARM's website [3].

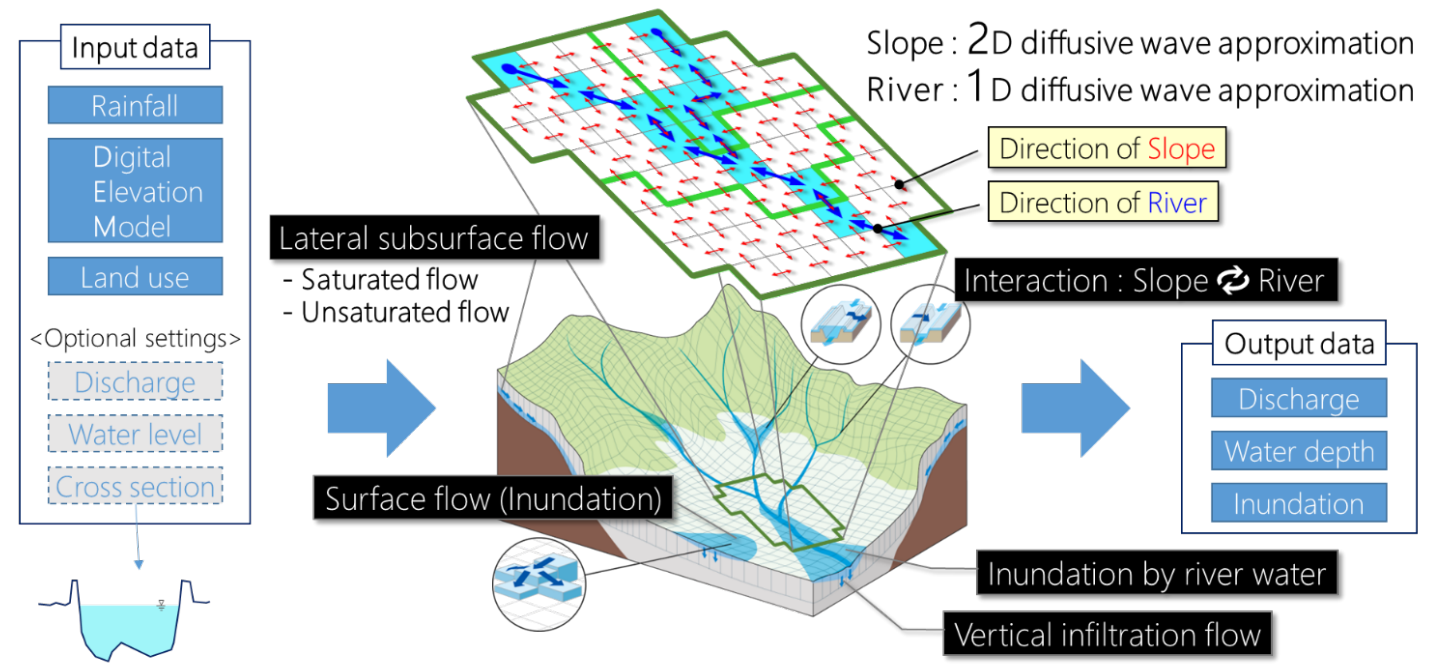

Figure 4: Conceptual scheme of the RRI model.

\subsection{Rainfall data}

In Japan, there are several types of rainfall radars at the present time that can be obtained in real time (see the top three in Table 1); rainfall observed using C-band Radar, rainfall analysed based on precipitation observed on the ground, and rainfall observed using X-band Radar. In this study, as a result of quantitative accuracy verification, Analysis Rainfall was used [4].

Rainfall predicted for the next several hours is provided by the Japan Meteorological Agency (JMA). There are two products of predicted rainfall (see the bottom two in Table 1); Nowcast Rainfall is provided for the next 1 hour at a spatial resolution of $250 \mathrm{~m} \times 250 \mathrm{~m}$; Forecast Rainfall is provided for the next 6 hours at $1 \mathrm{~km} \times 1 \mathrm{~km}$. In this study, we selected Forecast Rainfall to ensure as long a lead time as possible. This product, as shown Figure 5, combines the Moving Vector Analysis for the first about 3-hour prediction and the Numerical Meteorological Model for the last about 3-hour prediction. 
Evaluation of the Uncertainty of Flash Flood Prediction Using the RRI Model ... Y. Nakamura et al.

\begin{tabular}{|c|c|c|c|c|c|}
\hline Type & Rainfall products & $\begin{array}{c}\text { Spatial } \\
\text { resolution }\end{array}$ & $\begin{array}{c}\text { Time } \\
\text { interval }\end{array}$ & Delay time & $\begin{array}{c}\text { Predict } \\
\text { time }\end{array}$ \\
\hline Observation & C-band Radar & $250 \mathrm{~m} \times 250 \mathrm{~m}$ & 5 minutes & 1 minute & - \\
\hline Observation & Analysis Rainfall & $1 \mathrm{~km} \times 1 \mathrm{~km}$ & $\begin{array}{c}30 \\
\text { minutes }\end{array}$ & 13 minutes & - \\
\hline Observation & X-band Radar & $250 \mathrm{~m} \times 250 \mathrm{~m}$ & 1 minute & 1 minute & - \\
\hline Prediction & Nowcast Rainfall & $250 \mathrm{~m} \times 250 \mathrm{~m}$ & 5 minutes & 2 minutes & 1 hour \\
\hline Prediction & Forecast Rainfall & $1 \mathrm{~km} \times 1 \mathrm{~km}$ & $\begin{array}{c}30 \\
\text { minutes }\end{array}$ & 18 minutes & $\begin{array}{c}6 \\
\text { hours }\end{array}$ \\
\hline
\end{tabular}

Table 1: Rainfall products (present/forecast) and its characteristics.

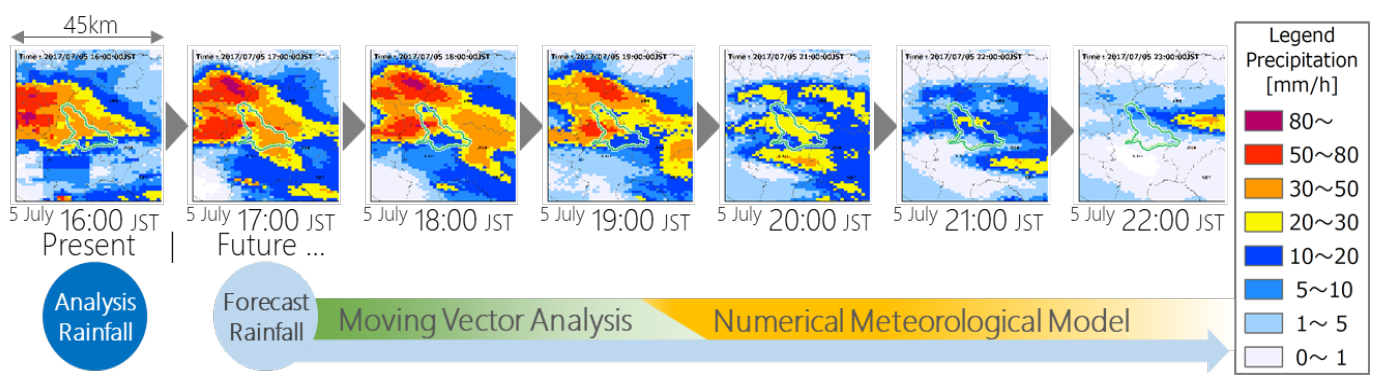

Figure 5: Distribution by Forecasted Rainfall around the Kagetsu River basin at 16 o'clock, July 5th 2017.

\subsection{Real-time flood prediction}

Real-time simulation predicted water levels every 30 minutes for the next 6 hours. The conditions of the river basin (e.g., soil moisture, river water level) were updated only with data from radar observation. A delay time of 18 minutes needed for analysis and data transfer was considered in calculation. Discharge calculated by the RRI model was converted to water level using the H-Q relational equation. The H-Q relational equation was created based on the data observed in 2012. Steps in flood forecasting simulation are shown below:

Step 1: Spin up: Carry out spin-up calculation utilizing the RRI model for about 5 days, in order to obtain the initial conditions.

Step 2: Archive the initial conditions: Archive the initial conditions on the river basin, such as water depth in slope and river channel cells, boundary discharge or water depth.

Step 3: Prepare rainfall data: Format data as input rainfall data for the RRI model. If there are missing data in the rainfall data, they should be interpolated from the nearest data.

Step 4: Run the RRI model: Run the RRI model for calculation using rainfall observed by radar for 30-minutes and using rainfall forecasted for the next 6 hours.

Step 5: Archive new conditions: Archive new conditions which were calculated using observation rainfall in order to use them as the initial conditions in the next step.

Step 6: Update the time: Update the time, return to Step 3, and repeat the same series of steps. 
Evaluation of the Uncertainty of Flash Flood Prediction Using the RRI Model ... Y. Nakamura et al.

\section{Results}

\subsection{Verification of rainfall: Analysis and Forecast Rainfall}

First, after comparing various radar rainfall products with ground rainfall, we verified the accuracy of the optimum radar product and Forecast Rainfall. For the accuracy verification of Forecast Rainfall, cumulative rainfall at each time was plotted in Figure 6, and we evaluated Forecast Rainfall using a single regression equation in which the y-axis intercept is zero. As a result, the rainfall for the initial 3 hours was predicted highly accurately with regression coefficient $\alpha$ ranging from 0.9 to 1.1 and determination coefficient R2 at approximately 0.9 . However, for the subsequent 3 hours, regression coefficient $\alpha$ and determination coefficient R2 become smaller as the lead time becomes longer. Therefore, longer the lead time, more likely the predicted rainfall is to be underestimated compared to radar-observed rainfall.

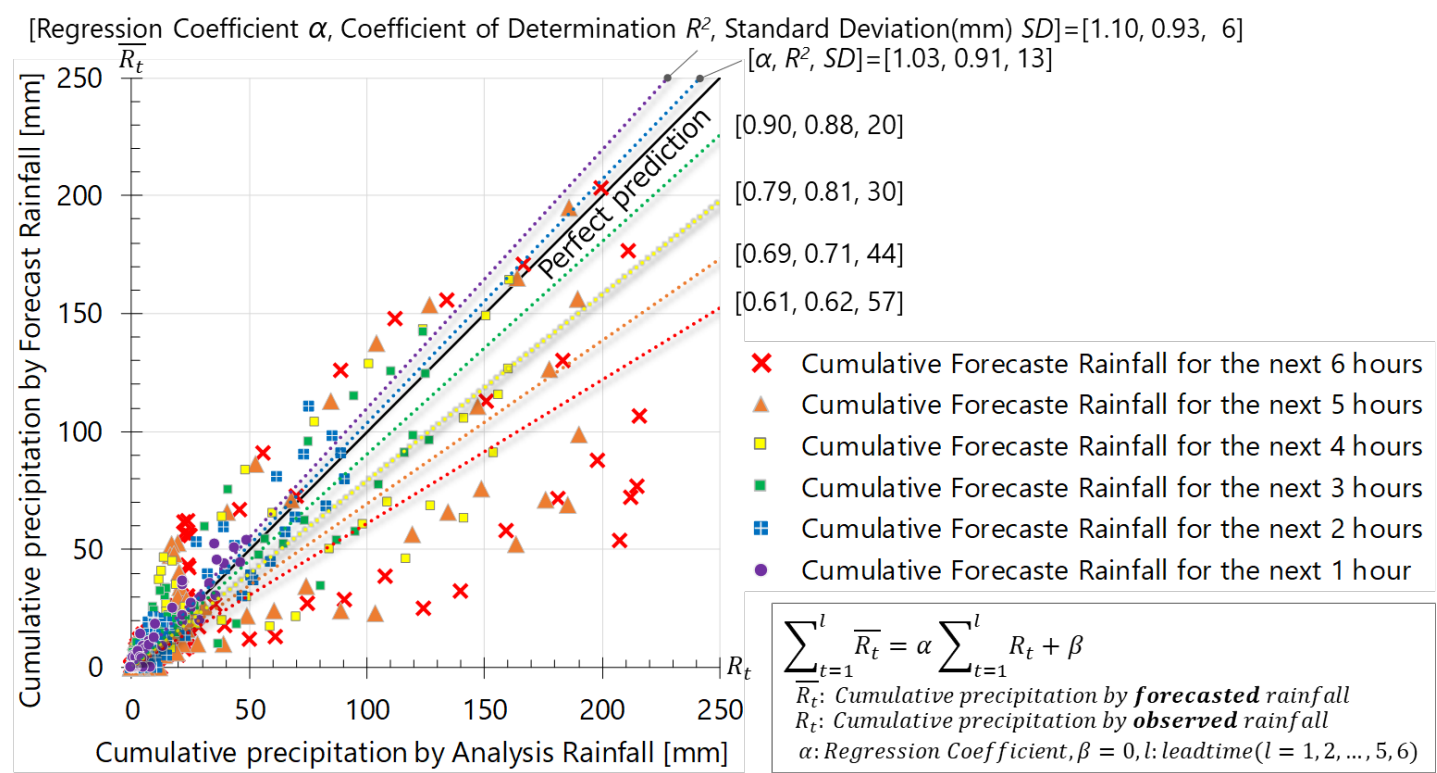

Figure 6: Correlation diagram of Analysis Rainfall and Forecast Rainfall, and its regression line.

\subsection{Flood prediction using the RRI model}

The water level observed at the Kagetsu Water gauging station was compared with the water level calculated by the RRI model. The comparison found that the peak error was $+0.2 \mathrm{~m}$ with a Nash-Sutcliffe Coefficient of 0.97 in this event. This result confirmed that the RRI model has high reproducibility. Figure 7 shows the water level predicted for the next 6 hours at 30-minute intervals during the July 2017 flood. Forecasted water levels No.1 (forecasted at 11:00) to No.4 (at 12:30) show an increase, but these water levels are underestimated. In addition, forecasted water levels No.5 (at 13:00) to No.11 (at 16:00) rise for the next 2-3 hours but thereafter decline. These results can be explained from Figures 8 and 9. Figure 8 shows the precipitation distribution of Analysis Rainfall and Forecast Rainfall at 12 o'clock on July 5th. At this time, Forecast Rainfall hardly predicts the rapid frontogenesis compared to Analysis Rainfall. Figure 9 shows the precipitation distribution of Analysis Rainfall and Forecast Rainfall at 15 o'clock on July 5th. At this time, the Moving Vector Analysis is capable of predicting the rapid frontogenesis for the next 3 hours from the initial rainfall distribution. For example, forecasted water level No.11 (at 16:00) exceeds Warning Level 4 (water level with high flood risk) at about 17 
Evaluation of the Uncertainty of Flash Flood Prediction Using the RRI Model ... Y. Nakamura et al.

o'clock, but eventually falls to Warning Level 3 (water level to start evacuation). After that, forecasted water levels No. 12 to No. 20 are reproduced to be roughly comparable to the calculated water level.

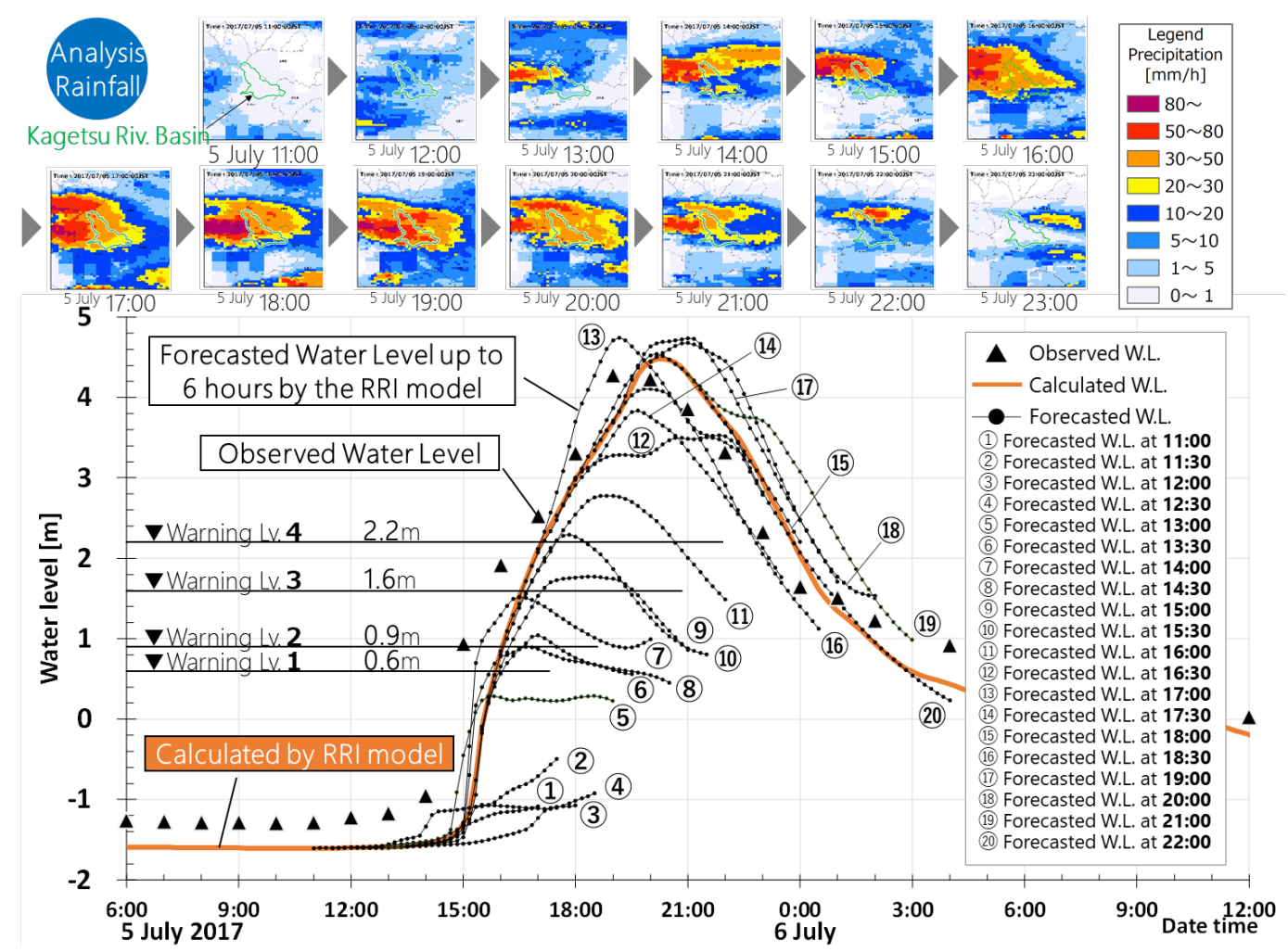

Figure 7: Calculated water levels by the RRI model and forecasted water levels for the next 6 hours.

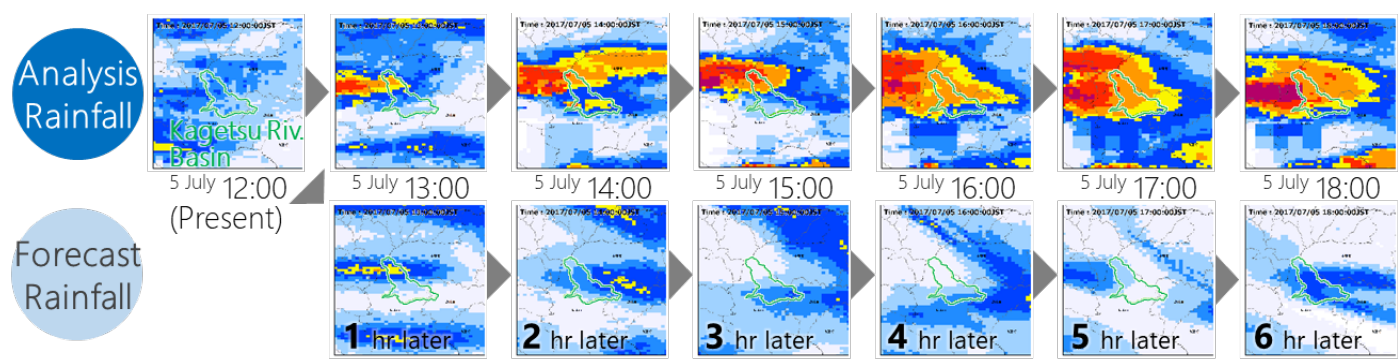

Figure 8: Analysis Rainfall and Forecast Rainfall at 12 o'clock, 5 July 2017 (Before the water level rises).

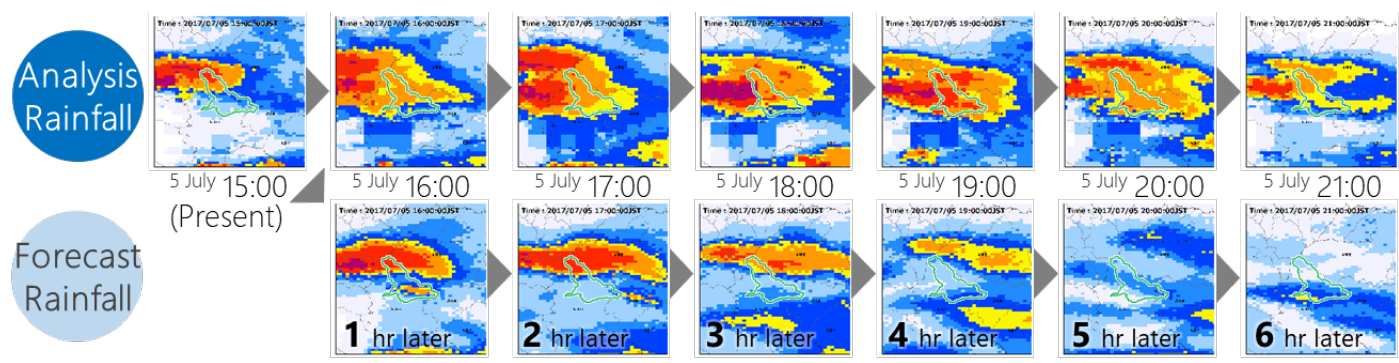

Figure 9: Analysis Rainfall and Forecast Rainfall at 15 o'clock, 5 July 2017 (while the water level is rising). 


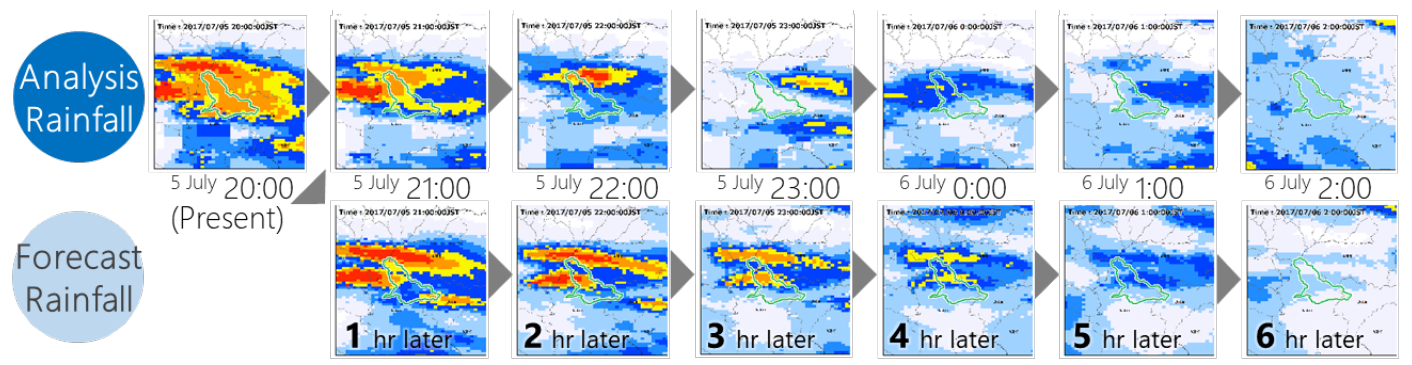

Figure 10: Analysis Rainfall and Forecast Rainfall at 20 o'clock, 5 July 2017 (when the water level peaks).

\subsection{Evaluation on uncertainty of flood prediction}

Figure 11-left is a box plot showing the uncertainty of the flood prediction in this event. Since the data assimilation to water level observed was not covered in this study, note that there was some error in water level even at the present time. The error is attributed to uncertainty rather than prediction originating in observed rainfall distribution, observed water level, conceptual of hydrological models, modeling processes, and the delay time of radar data. The error value is defined as the difference between the calculated value the observed value. When the difference is positive, the calculated water level is overestimated; when negative, underestimated. As a result of comparison between the calculated water level and the observed water level, at the present time, the minimum error of water level is estimated at $-2.25 \mathrm{~m}$, the maximum is $+0.63 \mathrm{~m}$, and the mean is $-0.33 \mathrm{~m}$. The evaluation also found that the mean error of the forecasted water level was approximately $-0.3 \mathrm{~m}$ in the prediction for the first 3 hours, $-0.53 \mathrm{~m}$ at the 4 th hour, $-0.75 \mathrm{~m}$ at the 5 th hour, and approximately $-0.97 \mathrm{~m}$ at the 6th hour. The range of error increases as the prediction is conducted further ahead in the future; when the water level is predicted 6 hours ahead from the present time, the minimum is $-4.38 \mathrm{~m}$, the maximum is $+0.63 \mathrm{~m}$, the median is $-0.45 \mathrm{~m}$, and the mean is $-0.97 \mathrm{~m}$.

\subsection{Flood prediction considering uncertainty}

Since this event was heavy rain caused by cumulonimbus clouds, it was difficult to predict rainfall using the Moving Vector Analysis. Despite such difficulty, river administrators must issue flood warnings, and the underestimation of water levels may cause a fatal situation. If an uncertainty distribution is available, it is possible for them to provide relevant organizations with forecasted water levels with a range of uncertainty. Therefore, error at each prediction time is taken as a bias, and water levels forecasted by the RRI model can be corrected. However, since correction depending on extreme error derived from the minimum and the maximum may compromise the reliability of flood prediction, we decided to make bias correction when the prediction error is within the range between the $25 \%$ value and the $75 \%$ value, considering the error to be statistically significant. Figure 11-right shows the forecasted water level (at 13:30) as an example. The water level forecasted by the RRI model is predicted to reach Warning Level 2 (water level calling for attention to flooding), and thereafter goes down below Warning Level 1 . However, considering the uncertainty range, the water level corrected using the 25\% value reaches Warning Level 4.

\subsection{Lead time for evacuation}

As in Figure 11-right, deterministic forecasting (forecasting without considering uncertainty; green dotted line) predicts at 15:30 that the water level may reach Warning Level 4 in this event; the lead time for evacuation is estimated to be 1 hour 10 minutes. On the other hand, flood prediction considering 
uncertainty (the 25\%-value line) predicted at 13:30 that the water level may reach Warning Level 4; the lead time is estimated to be 3 hours 10 minutes.
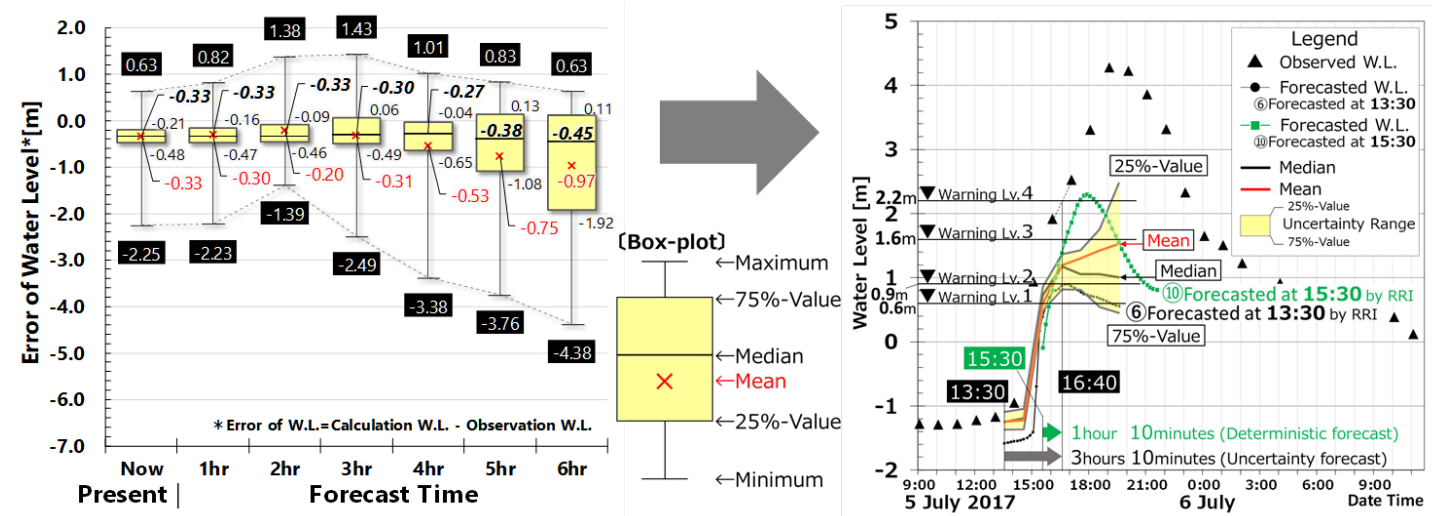

Figure 11: Evaluation of the uncertainty of flash flood prediction in an event and the bias correction of the forecasted water level (at 13:30).

\section{Conclusion}

In this study on the frontal heavy rain in July 2017, simulation was conducted for flash flood prediction using the RRI model for the next 6 hours, and predictive uncertainty was also evaluated. Although the RRI model was confirmed to have high reproducibility for this flood event, in real-time simulation, there was error in water levels calculated even for the present time. We also found that the error width increased as the prediction time became longer. In addition, the forecasted water level was corrected using the uncertainty found in this study. The results suggest that the accuracy of flash flood forecasting can be improved by considering uncertainty involved in prediction. Moreover, the lead time for safe evacuation can increase by 2 hours with bias correction compared with the lead time estimated from flood prediction without bias correction.

\section{Reference}

[1] Sayama, T., Ozawa, G., Kawakami, T., Nabesaka, S., and Fukami, K.: Rainfall-runoff-inundation analysis of the 2010 Pakistan flood in the Kabul River basin, Hydrological Sciences Journal - Journal des Sciences Hydrologiques, 57(2), 298-312, 2012.

[2] Sayama, T., Tatebe, Y., and Tanaka, S.: Hydrologic sensitivity of flood runoff and inundation:2011 Thailand floods in the Chao Phraya River basin, Nat. Hazards Earth Syst. Sci., 15, 1617-1630, 2015.

[3] RRI Model download website: http://www.icharm.pwri.go.jp/research/rri/rri_top.html, International Centre for Water Hazard and Risk Management (ICHARM), Public Works Research Institute (PWRI).

[4] JMA website : http://www.jma.go.jp/jma/indexe.html, Japan Meteorological Agency (JMA), Ministry of Land, Infrastructure, Transport and Tourism(MLIT). 